\title{
Excitatory Synaptic Drive and Feedforward Inhibition in the Hippocampal CA3 Circuit Are Regulated by SynCAM 1
}

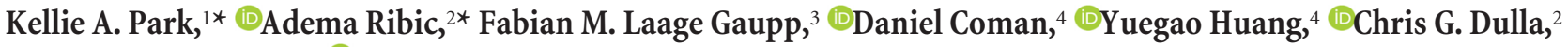 \\ Fahmeed Hyder, ${ }^{4,5}$ and $\odot$ Thomas Biederer ${ }^{2}$ \\ ${ }^{1}$ Department of Anesthesiology, Yale University School of Medicine, New Haven, Connecticut 06520, 2 Department of Neuroscience, Tufts University School \\ of Medicine, Boston, Massachusetts 02111, ${ }^{3}$ Institute of Clinical Neuroimmunology, Ludwig-Maximilians-University, 80539 Munich, Germany, \\ ${ }^{4}$ Department of Radiology and Biomedical Imaging, Yale University School of Medicine, New Haven, Connecticut 06520, and ${ }^{5}$ Department of Biomedical \\ Engineering, Yale University, School of Engineering and Applied Science, New Haven, Connecticut 06520
}

Select adhesion proteins control the development of synapses and modulate their structural and functional properties. Despite these important roles, the extent to which different synapse-organizing mechanisms act across brain regions to establish connectivity and regulate network properties is incompletely understood. Further, their functional roles in different neuronal populations remain to be defined. Here, we applied diffusion tensor imaging (DTI), a modality of magnetic resonance imaging (MRI), to map connectivity changes in knock-out (KO) mice lacking the synaptogenic cell adhesion protein SynCAM 1. This identified reduced fractional anisotropy in the hippocampal CA3 area in absence of SynCAM 1. In agreement, mossy fiber refinement in CA3 was impaired in SynCAM 1 K0 mice. Mossy fibers make excitatory inputs onto postsynaptic specializations of CA3 pyramidal neurons termed thorny excrescences and these structures were smaller in the absence of SynCAM 1. However, the most prevalent targets of mossy fibers are GABAergic interneurons and SynCAM 1 loss unexpectedly reduced the number of excitatory terminals onto parvalbumin (PV)-positive interneurons in CA3. SynCAM $1 \mathrm{KO}$ mice additionally exhibited lower postsynaptic GluA1 expression in these PV-positive interneurons. These synaptic imbalances in SynCAM $1 \mathrm{KO}$ mice resulted in CA3 disinhibition, in agreement with reduced feedforward inhibition in this network in the absence of SynCAM 1-dependent excitatory drive onto interneurons. In turn, mice lacking SynCAM 1 were impaired in memory tasks involving CA3. Our results support that SynCAM 1 modulates excitatory mossy fiber inputs onto both interneurons and principal neurons in the hippocampal CA3 area to balance network excitability.

Key words: Cadm; hippocampus; interneuron; nectin-like; synapse; SynCAM

Significance Statement

This study advances our understanding of synapse-organizing mechanisms on two levels. First, the data support that synaptogenic proteins guide connectivity and can function in distinct brain regions even if they are expressed broadly. Second, the results demonstrate that a synaptogenic process that controls excitatory inputs to both pyramidal neurons and interneurons can balance excitation and inhibition. Specifically, the study reveals that hippocampal CA3 connectivity is modulated by the synapseorganizing adhesion protein SynCAM 1 and identifies a novel, SynCAM 1-dependent mechanism that controls excitatory inputs onto parvalbumin-positive interneurons. This enables SynCAM 1 to regulate feedforward inhibition and set network excitability. Further, we show that diffusion tensor imaging is sensitive to these cellular refinements affecting neuronal connectivity.

\section{Introduction}

Neuronal surface interactions instruct connectivity though processes that include adhesion and repulsion (Benson et al., 2001;

Received Jan. 18, 2016; revised June 1, 2016; accepted June 2, 2016.

Author contributions: K.A.P., A.R., F.M.L.G., C.G.D., F.H., and T.B. designed research; K.A.P., A.R., F.M.L.G., D.C., Y.H., and C.G.D. performed research; K.A.P., A.R., F.M.L.G., D.C., Y.H., and C.G.D. analyzed data; T.B. wrote the paper.

This work was supported by the National Institutes of Health (Grant T32 GM086287 to K.A.P., Grant NS076885 to C.G.D., Grants R01 MH067528 and P30 NS052519 to F.H., and Grant R01 DA018928 to T.B.) and a Knights Templar Career Starter Research Grant (A.R.). We thank the Yale Cellular Neuroscience, Neurodegeneration and Repair
Zipursky and Sanes, 2010) and synapse-organizing adhesion proteins contribute to these processes through regulating the development of synaptic contacts. Multiple trans-synaptic complexes

(CNNR) Program for imaging core access and the Tufts Center for Neuroscience Research for support under National Institutes of Health Grant P30 NS047243.

The authors declare no competing financial interests.

*K.A.P. and A.R. contributed equally to this work.

K.A. Park's present address: Department of Anesthesiology, Schneck Medical Center, Seymour, IN 47274.

F.M. Laage Gaupp's present address: New York Presbyterian Hospital, Department of Surgery, New York, NY 10032. 
organize excitatory and inhibitory synapses (Shen and Scheiffele, 2010; Missler et al., 2012). One reason for the molecular diversity of these complexes could be that they act preferentially in select brain regions, but this remains to be defined in a systematic manner. Moreover, it is incompletely understood to what extent these proteins control the synaptic integration of distinct neuron types into circuits.

Understanding the roles of synapse-organizing proteins is not just important in determining how neurons are wired into networks; these proteins also affect excitatory/inhibitory (E/I) balance (Südhof, 2008; Betancur et al., 2009), which is required for information coding in neuronal networks. A disruption of this balance, such as when synapse-organizing proteins are mutated, can underlie neuropsychiatric diseases and autism spectrum disorders (Seshadri et al., 2013; Nelson and Valakh, 2015). Defining the effects of synapseorganizing proteins will thus elucidate how network balance is set on a synaptic level. Further, this can prepare us to address whether disease-linked molecular aberrations affect the connectivity of select brain regions rather than impairing all synaptic connections.

The expression of the synaptic cell adhesion molecule SynCAM 1 (also known as Cadm1 and nectin-like 2 protein) across forebrain neurons (Thomas et al., 2008) makes it a candidate to evaluate differential regional roles of synapse-organizing proteins. SynCAM 1 belongs to a family of four homophilic and heterophilic membrane proteins of the Ig superfamily, is expressed during the peak period of synaptogenesis, and remains present into adulthood (Fogel et al., 2007; Thomas et al., 2008). It marks the edge of excitatory postsynaptic sites (Perez de Arce et al., 2015) and is sufficient to induce functional excitatory presynaptic specializations (Biederer et al., 2002; Fogel et al., 2007). Studies of the hippocampal CA1 area in knock-out (KO) and overexpressor mice have shown that SynCAM 1 is required and sufficient to promote excitatory synaptic inputs to excitatory neurons in vivo (Robbins et al., 2010).

Here, we applied diffusion tensor imaging (DTI), a modality of MRI, to investigate anatomical changes in SynCAM $1 \mathrm{KO}$ mice through characterization of fiber tracts (Oguz et al., 2012). Together with changes in other select brain regions, DTI showed a reduction in fractional anisotropy (FA) in the hippocampal CA3 area of SynCAM 1 KO mice. In agreement, the developmental refinement of mossy fibers was altered in the absence of SynCAM 1. To investigate corresponding synaptic changes, we analyzed two neuronal populations that receive mossy fiber inputs, GABAergic interneurons and excitatory pyramidal neurons. This revealed a SynCAM 1-dependent mechanism that controls excitatory inputs onto parvalbumin (PV)-positive interneurons in the $\mathrm{CA} 3$ area. In addition, CA3 pyramidal neurons exhibited smaller thorny excrescences (TEs) and had fewer distal spines in mice lacking SynCAM 1. These synapse-organizing roles of SynCAM 1 in CA3 are physiologically relevant and its loss resulted in profound disinhibition. This supports a function of SynCAM 1 in restricting network excitability through promoting glutamatergic inputs to interneurons. The CA3 area serves as association network (Rolls, 2013) and associative memory functions that involve CA3 were impaired in SynCAM 1 KO mice.

Our results support that synapse-organizing proteins can have pronounced effects in distinct brain regions and different neuron types, with SynCAM 1 guiding excitatory inputs onto both pyra-

Correspondence should be addressed to Thomas Biederer, Department of Neuroscience, Tufts University School of Medicine, 136 Harrison Avenue, Boston, MA 02111. E-mail: thomas.biederer@tufts.edu.

DOI:10.1523/JNEUROSCI.0189-16.2016

Copyright $\odot 2016$ the authors $\quad 0270-6474 / 16 / 367465-12 \$ 15.00 / 0$ midal neurons and GABAergic interneurons in the CA3 area. These findings provide evidence that E/I balance can be controlled by synaptogenic mechanisms that set the ratio of excitatory inputs onto principal neurons and interneurons in the same circuit.

\section{Materials and Methods}

Animals. SynCAM 1 KO mice generously provided by Dr. T. Momoi (National Institute of Neuroscience, Tokyo, Japan; Fujita et al., 2006) were back-crossed on a C57BL/6J background for $>10$ generations. Mice were bred as heterozygotics and only male wild-type (WT) and KO littermates were analyzed, except for PV immunostaining studies, which included female mice. All procedures were approved by the Institutional Animal Care and Use Committee and in compliance with National Institutes of Health guidelines.

Antibodies. Primary antibodies used in this study were polyclonal rabbit anti-Calbindin D-28k (Swant), polyclonal goat anti-PV (Swant; PV235), monoclonal rabbit anti-PSD-95 (Cell Signaling Technology; D27E11), monoclonal mouse anti-VGlut1 (NeuroMab; clone N28/9), monoclonal mouse anti-NeuN (Millipore; clone A60), monoclonal chicken anti-SynCAM 1 (MBL Laboratories; CM004-3, clone 3E1), polyclonal rabbit anti-GluA4 (Millipore; AB1508), polyclonal rabbit antiGluA1 (Millipore; PC246). Secondary antibodies were goat anti-rabbit Alexa Fluor 488 or Alexa Fluor 555, goat anti-mouse IgG1 Alexa Fluor 488 or Alexa Fluor 555 (Invitrogen), donkey anti-goat 647 (Invitrogen) and goat anti-chicken 488 (Invitrogen).

Immunohistochemistry. Mice were transcardially perfused with $4 \%$ paraformaldehyde (PFA), fixed brains were cryoprotected, sectioned on a Leica 2800 cryostat, and free floating sections were stored in PBS before processing as described below. Mice were perfused at postnatal day 28 (P28) unless indicated otherwise.

For mossy fiber staining, sections were blocked at room temperature (RT) for $1 \mathrm{~h}$ in $3 \%$ horse serum, $0.1 \%$ Triton-X in PBS, incubated $24 \mathrm{~h}$ at $4^{\circ} \mathrm{C}$ with anti-calbindin D-28k antibodies (1:2000 in blocking solution), washed, incubated $1 \mathrm{~h}$ at RT with secondary antibodies (1:2000), washed, and mounted. NeuN immunostaining was performed as above except that $3 \%$ normal goat serum was used for blocking and primary and secondary antibodies were used at 1:1000.

Timm's staining was performed as described previously (Schwegler et al., 1988). Briefly, floating sections were immersed in $1.2 \%$ sodium sulfide for $2 \mathrm{~h}$ at RT, then fixative for $20 \mathrm{~min}$ at RT with $1.25 \%$ glutaraldehyde/1\% PFA in PBS, and mounted.

For SynCAM 1, vGlut1, PSD-95, and PV immunohistochemistry, brains were immediately postfixed in $4 \%$ PFA at $4^{\circ} \mathrm{C}$ overnight. For SynCAM 1 immunohistochemistry, coronal sections of $60 \mu \mathrm{m}$ were cut using a vibratome (Leica 1500). For PV, vGlut1, and PSD-95 immunohistochemistry, fixed brains were dissected so that the sections were cut parallel to the long hippocampal axis as described previously (Fukuda and Kosaka, 2000). In short, the hippocampal formation, along with the overlying neocortex, was removed from the brainstem and cut into three blocks (dorsal, medial, and ventral). The surface of the neocortex was embedded in 3\% agarose and glued to the vibratome stage. Sectioning started at the side of the hippocampus that was previously facing the brainstem. Medial and ventral parts were sectioned at $80 \mu \mathrm{m}$ thickness using a vibratome (Leica 1500). For individual detection of SynCAM 1, antibodies were applied at 1:1000 for $24 \mathrm{~h}$ at $4^{\circ} \mathrm{C}$ to sections in a solution containing $3 \%$ normal horse serum and $0.05 \%$ Triton X-100 in PBS. For co-immunostainings, primary antibodies were applied sequentially (vGlut1, 1:200, for $48 \mathrm{~h}$; PV, 1:1000, for $24 \mathrm{~h}$; PSD-95, 1:500, for $24 \mathrm{~h}$; SynCAM 1, 1:1000, for $24 \mathrm{~h}$; all at $4^{\circ} \mathrm{C}$ ) to sections in a solution containing $3 \%$ normal horse serum and $0.05 \%$ Triton X-100 in PBS. Sections were washed, incubated for $2 \mathrm{~h}$ at RT with secondary antibodies (1:1000), washed, and mounted (Aqua-Poly/Mount; Polysciences).

For co-staining of glutamate receptors with PV, brains were split into two halves sagittally before cryoprotection and coronal sectioning. Sections containing the hippocampus were blocked as above and then sequentially incubated with primary antibodies against PV (1:1000), and then VGlut1 (1:200) and GluA1 (1:200), or vGlut1 (1:200) and GluA4 
(1:500; see Pelkey et al., 2015). All antibodies were diluted in $0.1 \%$ Triton, $3 \%$ normal horse serum in PBS and incubations were for $24 \mathrm{~h}$ at $4^{\circ} \mathrm{C}$.

Biolistic labeling. Biolistic labeling was performed as described previously (Staffend and Meisel, 2011; Giza et al., 2013). Briefly, brains were removed from transcardially perfused mice, postfixed with 4\% PFA for $1 \mathrm{~h}$, and $300 \mu \mathrm{m}$ sections were obtained on a Vibratome 1000 (Warner Instruments). Tungsten particles were coated with $1,1^{\prime}$-dioctadecyl$3,3,3^{\prime}, 3^{\prime}$-tetramethylindocarbocyanine perchlorate (DiI; Invitrogen) and delivered using a Helios Gene Gun System (Bio-Rad). After incubation for $20 \mathrm{~h}$ at $4^{\circ} \mathrm{C}$ in PBS, sections were fixed for $4-6 \mathrm{~h}$ and mounted.

Microscopy and image analysis. Images for calbindin were obtained with a laser scanning confocal microscope (LSM 710; Zeiss) and Zeiss EC Plan-Neofluar $\times 20$ air or $\times 63$ Plan Apo oil-immersion objectives, and Zen software. ImageJ version $1.45 \mathrm{~S}$ software was used for image quantifications. Calbindin immunostainings were analyzed manually (midpoint, CA3 striatum lucidum) from maximum intensity projections.

Images from Timm's staining were obtained with a PerkinElmer UltraVIEW spinning disc confocal microscope using light microscopy settings with a $20 \times$ CFI Plan Apo air objective and a Hamamatsu C9100-50 camera. Pixel density was measured using ImageJ and normalized to background.

DiI labeled neurons were imaged on PerkinElmer UltraVIEW spinning disc confocal microscope with a $100 \times$ CFI Plan Apo VC oilimmersion objective, using this setup with a neon/argon laser. $Z$-stacks for DiI were collapsed into projection images. TE analysis was restricted to secondary branches because primary branches were not as consistently populated.

Overview images for SynCAM 1 immunohistochemistry were obtained using a Keyence BZ-X700 epifluorescence microscope. Additional images of SynCAM 1 immunostaining from mossy fiber regions were obtained with a laser scanning confocal microscope (TCS SPE; Leica Microsystems) using a $20 \times$ air objective ( 0.5 numerical aperture, NA).

Simultaneous detection of SynCAM 1, vGlut1 and PV from tangential sections was performed on a laser scanning confocal microscope (TCS SPE; Leica Microsystems) using a $63 \times$ oil-immersion objective (1.3 NA) and Leica LAS software at $2048 \times 2048$ resolution. Images were a series of 3 optical sections $0.5 \mu \mathrm{m}$ apart.

vGlut1 and PSD-95 immunostainings were obtained using a confocal microscope (TCS SPE; Leica Microsystems) with a $63 \times$ oil-immersion objective (1.3 NA) and Leica LAS software at $2048 \times 2048$ resolution. Up to 14 scans were averaged to obtain the best resolution and the pinhole size was set to 1 . Single optical sections were analyzed using ImageJ. Briefly, background was subtracted from both channels before thresholding. Images were then binarized and size and density of puncta in stratum lucidum was determined using Particle Analyzer in ImageJ, with a cutoff value of $0.1 \mu \mathrm{m}^{2}$. Four to 10 hippocampal sections were analyzed per animal and approximately five images encompassing the entire stratum lucidum were collected per section.

Images for vGlut1 and PV from tangential hippocampal sections and vGlut1, GluA1, GluA4, and PV from coronal sections were obtained with a laser scanning confocal microscope (TCS SPE and SP8; Leica Microsystems) using a $63 \times$ oil-immersion objective (1.3 NA) and Leica LAS software at $2048 \times 2048$ resolution. Up to 14 scans were averaged to obtain the best resolution and the pinhole size was set to 1 . To collect as many PV-positive branches as possible, images were acquired as $Z$-stacks of regions of interest (ROI) in stratum lucidum at $0.5 \mu \mathrm{m}$ steps intervals. The entire span of stratum lucidum was imaged per slice (five to seven images) and four to eight hippocampal sections were imaged per animal. Using ImageJ, background was subtracted uniformly in all images. Channels were separated and single optical sections containing PV-positive dendritic segments were isolated for further analysis. PV-positive dendritic segments were delineated with a margin of $\sim 1 \mu \mathrm{m}$ surrounding them. vGlut1, GluA1, and GluA4 channels were thresholded, binarized, and particles $>0.1 \mu \mathrm{m}^{2}$ within PV-specified ROIs were analyzed using Particle Analyzer in ImageJ.

DTI and analysis. Mouse brains were processed for DTI at P28. Whole brains were obtained from transcardially perfused mice and incubated in $4 \%$ PFA for 20-29 d before DTI to avoid expansion artifacts. DTI datasets were obtained on a 9.4 T horizontal bore MRI scanner (Bruker) with a custom-made ${ }^{1} \mathrm{H}$ radio frequency volume coil (4 cm diameter). Diffusion tensor calculations were performed as described previously (Duque et al., 2012). FA images were generated with BioImage Suite (http://www. bioimagesuite.org/). Anatomical images were nonrigidly registered to a reference isotropic anatomical image $(100 \mu \mathrm{m})$ using nonlinear warping (Papademetris et al., 2001; Duque et al., 2012). Transformations were used to warp the FA maps to the same isotropic reference, followed by calculation of mean and SD FA maps. Two-tailed $t$ test maps were generated to define the ROIs for which pixel-by-pixel FA differences between groups were significant $(p<0.05)$. Average FA value and corresponding SD were calculated for each ROI in each animal and then FA average over the whole group in the same ROI was calculated. For CA3 ROIs, a separate analysis was done for the left, right, and both left and right regions. Final statistical comparison between WT and KO groups was done using two-tailed $t$ test analysis.

Electrophysiological studies. Hippocampal brain slices containing CA3 and dentate gyrus (DG) $(400 \mu \mathrm{m})$ were prepared from 4- to 6-week-old male SynCAM 1 KO mice and WT littermates. Briefly, mice were anesthetized with isoflurane, decapitated, and brains were rapidly removed and placed in chilled $\left(4^{\circ} \mathrm{C}\right)$ low- $\mathrm{Ca}^{2+}$, low- $\mathrm{Na}^{+}$slicing solution containing the following (in mM): 234 sucrose, 11 glucose, $24 \mathrm{NaHCO}_{2}, 2.5 \mathrm{KCl}$, $1.25 \mathrm{NaH}_{2} \mathrm{PO}_{4}, 10 \mathrm{MgSO}_{4}$, and $0.5 \mathrm{CaCl}_{2}$ equilibrated with a mixture of $95 \% \mathrm{O}_{2}: 5 \% \mathrm{CO}_{2}$. The brain was glued to the slicing stage of a Vibratome 3000 sectioning system and slices were cut in a horizontal orientation. Slices were then incubated in $32^{\circ} \mathrm{C}$ oxygenated aCSF containing the following (in mM): $126 \mathrm{NaCl}, 2.5 \mathrm{KCl}, 1.25 \mathrm{NaH}_{2} \mathrm{PO}_{4}, 1 \mathrm{MgSO}_{4}, 2 \mathrm{CaCl}_{2}, 10$ glucose, and $26 \mathrm{NaHCO}_{2}$ for $1 \mathrm{~h}$ and then allowed to cool to room temperature. Slices were placed in an interface chamber maintained at $34^{\circ} \mathrm{C}$, superfused with oxygenated aCSF at $2 \mathrm{ml} / \mathrm{min}$, and mossy fibers were stimulated with a tungsten concentric bipolar electrode placed in the DG granule cell layer. Electrical stimulation consisted of 5-20 $\mu \mathrm{A}$, $50-750 \mu$ s pulses at $30 \mathrm{~s}$ intervals delivered by a stimulus isolator (World Precision Instruments). Glass micropipettes (resistance $\cong 1 \mathrm{M} \Omega$ ) were filled with aCSF and placed in area CA3 stratum radiatum. Electrophysiological data were recorded with an Axon Multiclamp 700A amplifier and Digidata 1322A digitizer (sampling rate $20 \mathrm{kHz}$ ) with pClamp software (Molecular Devices). Threshold stimulation intensity was identified as the minimum amount of current required to elicit a detectable cortical field potential response $(\geq 0.05 \mathrm{mV})$. Experiments were conducted in either control aCSF or aCSF containing $10 \mu \mathrm{M}$ SR-95531 (gabazine; Sigma-Aldrich) to block $\mathrm{GABA}_{\mathrm{A}}$ receptors. Peak negative slope and amplitude were measured in the CA3 field potential recording using ClampFit (Molecular Devices).

Behavioral studies. Contextual fear conditioning (CFC) was measured by administering three foot shocks to the animals $(0.3 \mathrm{~mA}, 2 \mathrm{~s}$ duration, $60 \mathrm{~s}$ apart) within a specific context. Mice were returned to context after $60 \mathrm{~min}$ in their home cage for a $5 \mathrm{~min}$ test and freezing responses were scored every $5 \mathrm{~s}$. This was repeated $24 \mathrm{~h}$ later. Inhibitory avoidance was measured using a separate cohort of animals in a step-through inhibitory avoidance apparatus. Mice were placed in the testing apparatus "light" side, facing a wall opposite a guillotine door. After $30 \mathrm{~s}$, the door opened and, if the animal crossed through the door to the "dark" side, the animal received a $0.3 \mathrm{~mA}, 2 \mathrm{~s}$ foot shock. After $1 \mathrm{~h}$, latency for step-through to the "dark" side was recorded and this was repeated at $24 \mathrm{~h}$.

Data and statistical analysis. All quantitated analyses were performed blinded to the condition. Statistical analyses were performed with GraphPad Prism software using unpaired, parametric Student's $t$ test or two-way ANOVA with Bonferroni's post hoc test unless stated otherwise. For statistical analyses of immunohistochemical data, $n$ was taken as the number of animals used per experimental group. Data are represented as mean \pm SEM with ${ }^{\star} p<0.05,{ }^{* *} p<0.01$, and ${ }^{\star *} p<0.001$.

\section{Results}

Select brain connectivity changes in absence of SynCAM 1

Aiming to survey broader connectivity changes upon loss of SynCAM 1 in KO mice, we used DTI to estimate white matter microarchitecture noninvasively. DTI allows tracking major fiber tract direction and connectivity by quantifying the restricted and 

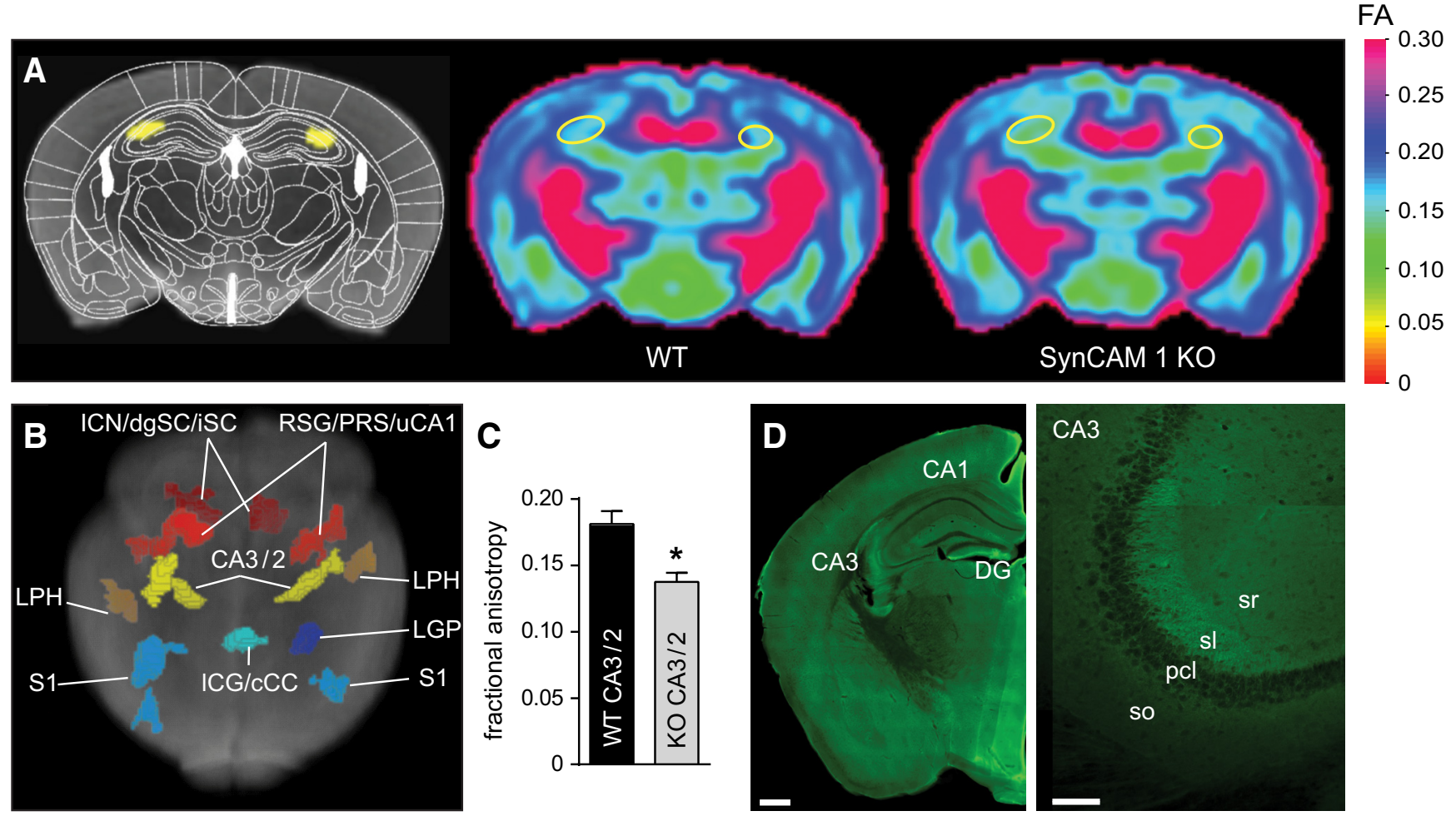

Figure 1. Loss of SynCAM 1 affects connectivity in select brain regions. A, Left, diagram from the Paxinos atlas (Paxinos and Franklin, 2001) for anatomic overlay. Center, Average FA map of a composite coronal slice from WT mouse littermate control brains at P28. Right, SynCAM 1 KO brains. Yellow ellipsoids mark hippocampal CA3 areas with reduced FA in K0 brains. B, 3D rendering of regions with significant FA differences of WT and SynCAM $1 \mathrm{KO}$ littermates ( $n=6$ male mice each). Bilateral FA reduction was measured in the hippocampal CA3/CA2 areas (yellow; K0 $78 \pm 7 \%$ of WT, $p<0.00004$, two-tailed $t$ test) and lateral posterior hippocampus (LPH, brown; K0 $78 \pm 7 \%, p<0.00028$ ). FA was increased in retrosplenial granular cortex/presubiculum/upper CA1 (RSG/PRS/UCA1, red; K0 $130 \pm 14 \%, p<0.00004$ ), parts of somatosensory cortex (S1, light blue; K0 $125 \pm 10 \% p<0.00009$ ), subcortical intercollicular nucleus/deep gray layer of superior colliculus/intermediate white and gray layers of superior colliculus (ICN/dgSC/iSC, dark red; KO $124 \pm 12 \%, p<0.0002$ ), and lower cingulum and central corpus callosum (ICG/CCC, light green; K0 $134 \pm 19 \%, p<0.0014$ ). The lateral globus pallidus (LGP) was the only region with unilateral FA changes (left hemisphere, blue; $K 0120 \pm 11 \% p<0.0002$ ). See Table 1 for regional differences. C, Bilateral FA reduction in the CA3 area of K0 compared with WT (KO $76 \pm 5 \% p=0.023, n=6$ male mice each group). $\boldsymbol{D}$, Left, Coronal section immunostained at P28 for SynCAM 1 with hippocampal areas marked. Right, Strong SynCAM 1 staining in CA3 stratum lucidum (sl). pcl, Pyramidal cell layer; so, stratum oriens; sr, stratum radiatum. Scale bars: overview, $1 \mathrm{~mm}$; inset, $100 \mu \mathrm{m}$.

Table 1. FA differences between SynCAM 1 KO and WT mice

\begin{tabular}{lllll}
\hline Region & FA (K0) & FA (WT) & $\Delta$ & $p$-value \\
\hline CA3/CA2 & $0.14 \pm 0.01$ & $0.18 \pm 0.01$ & -0.04 & 0.00004 \\
LPH & $0.15 \pm 0.01$ & $0.19 \pm 0.02$ & -0.04 & 0.0003 \\
RSG/PRS/uCA1 & $0.22 \pm 0.01$ & $0.17 \pm 0.01$ & 0.05 & 0.00004 \\
S1 & $0.19 \pm 0.01$ & $0.15 \pm 0.01$ & 0.04 & 0.00008 \\
ICN/dgSC/iSC & $0.25 \pm 0.01$ & $0.20 \pm 0.01$ & 0.05 & 0.0002 \\
ICG/CCC & $0.31 \pm 0.03$ & $0.23 \pm 0.03$ & 0.08 & 0.0014 \\
LGP & $0.36 \pm 0.01$ & $0.30 \pm 0.02$ & 0.06 & 0.0002 \\
\hline
\end{tabular}

Analyzed ROIs were hippocampal CA3/CA2 areas, lateral posterior hippocampus (LPH), retrosplenial granular cortex/presubiculum/upper CA1 (RSG/PRS/uCA1), parts of somatosensory cortex (S1), subcortical intercollicular nucleus/deep gray layer of superior colliculus/intermediate white and gray layers of superior colliculus (ICN/dgSC/iSC), lower cingulum and central corpus callosum (ICG/CCC), and lateral globus pallidus (LGP). $p$-values, two-tailed $t$ test. $\Delta$, difference between $F A$ values for $K 0$ and WT. See Figure $1 B$ for ROI locations.

directional diffusion of water molecules as FA (Chahboune et al., 2007). We measured FA in brains of male mice at P28, when most developmental processes are completed. DTI datasets were obtained from brains of perfused mice, registered to a reference anatomical image, and pixel-by-pixel FA differences between SynCAM $1 \mathrm{KO}$ and WT littermates were analyzed. This determined a significant bilateral FA reduction in mice lacking SynCAM 1 compared with WT in the hippocampal CA3/CA2 areas and the lateral posterior hippocampus (Fig. $1 A-C$, Table 1 ). We additionally measured higher FA in KO than in WT mice in the bilateral retrosplenial granular and retrosplenial agranular cortices (Fig. 1B, Table 1). SynCAM 1 KO mice exhibited higher FA than WT in areas of sensory cortex and subcortical regions, as well as posterior hypothalamic regions (Fig. $1 B$, Table 1 ).

The SynCAM 1-dependent FA changes in hippocampal CA3 and the well defined connectivity of this region offered the opportunity to investigate SynCAM 1 roles in this brain area. We therefore performed immunohistochemical staining of mice at P28 for SynCAM 1. This detected its prominent expression in CA3 including stratum lucidum, where mossy fibers terminate (Fig. 1D), in agreement with the expression of SynCAM 1 mRNA in granule cells of the DG and pyramidal cells of the CA fields (Thomas et al., 2008).

\section{SynCAM 1 modulates mossy fiber innervation}

Aiming to delineate SynCAM 1-dependent connectivity changes in the CA3 area, we next immunostained hippocampal sections from WT and SynCAM $1 \mathrm{KO}$ mice for calbindin to visualize mossy fiber projections of DG granule cells (Fig. 2A). The length of the suprapyramidal and infrapyramidal mossy fiber bundle, their distance, and the number of crossing fibers were unaffected by loss of SynCAM 1 (data not shown). However, the width of the main suprapyramidal mossy fiber bundle was reduced in $\mathrm{KO}$ mice at P14 compared with WT (Fig. 2B). Further, we measured a developmental decrease in the width of the suprapyramidal mossy fiber bundle in WT mice between P14 and P28. This pruning did not occur in $\mathrm{KO}$ mice, resulting in wider suprapyramidal mossy fiber bundles at P28 (Fig. 2B). These changes, though 

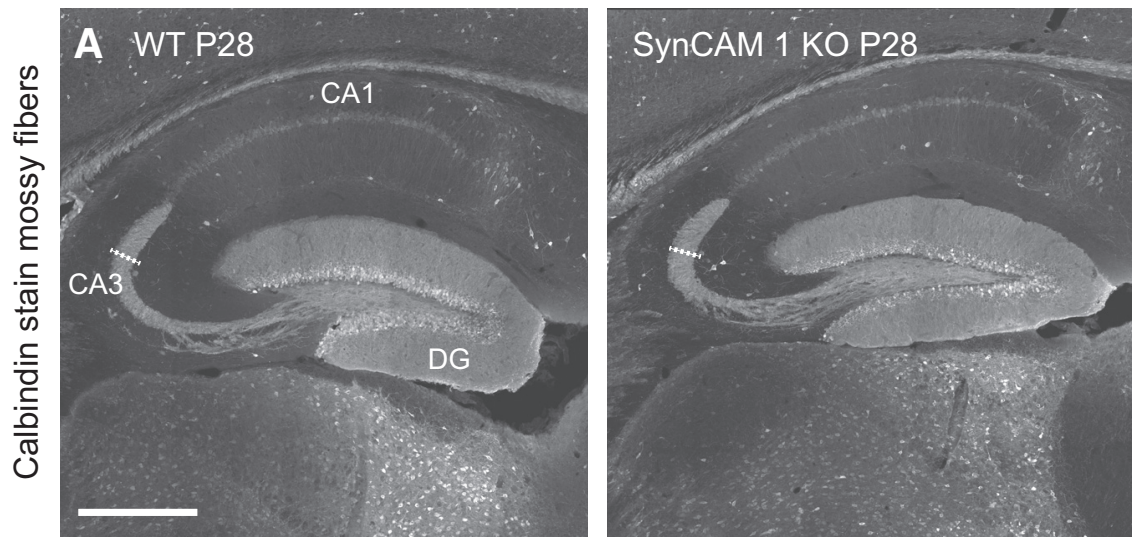

B

- WT

$\circ \mathrm{KO}$
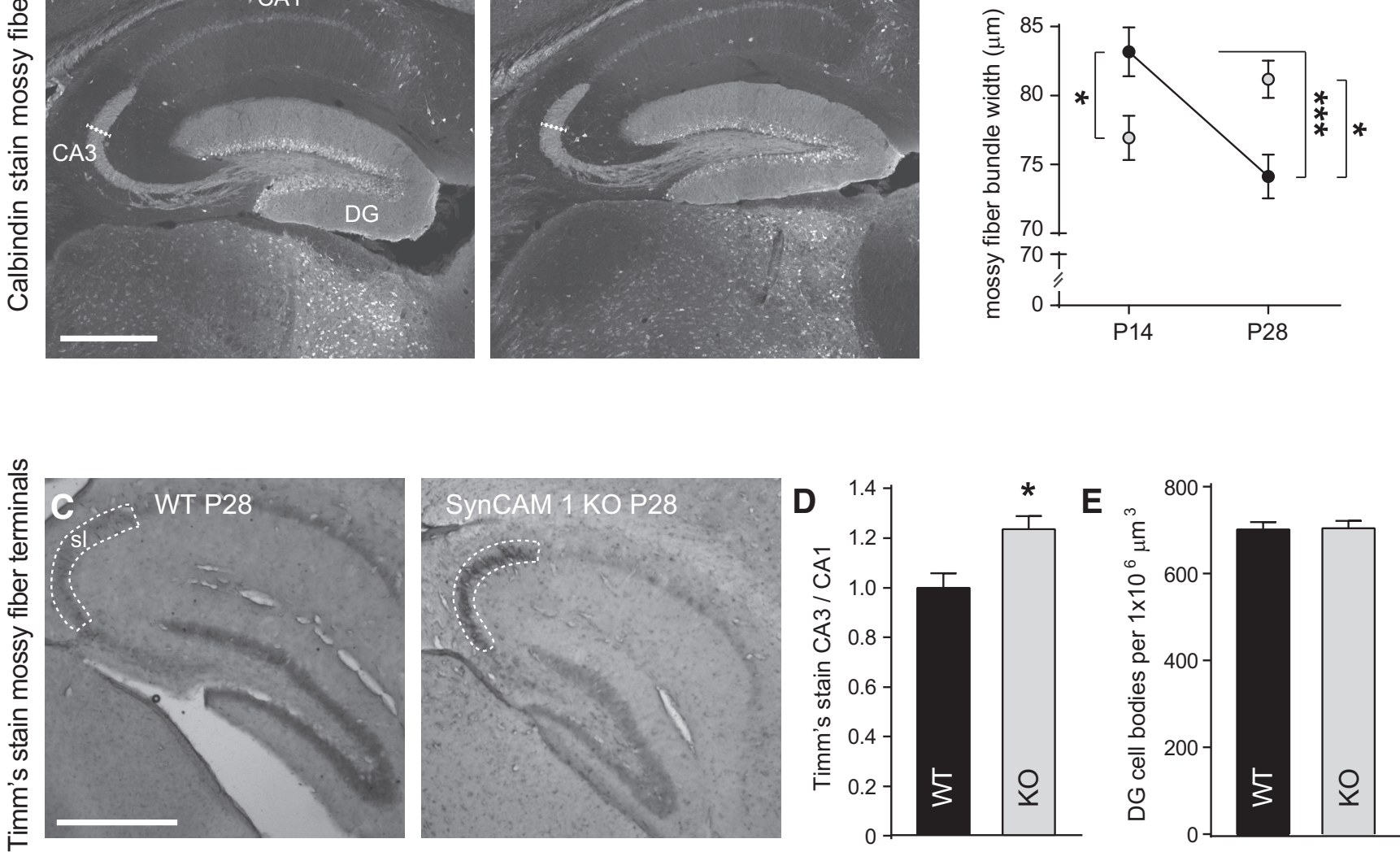

Figure 2. SynCAM 1-dependent changes in mossy fiber projections and target innervation in the hippocampal CA3 area. $\boldsymbol{A}$, Calbindin immunostaining of hippocampal sections to label mossy fibers in WT (left) and SynCAM 1 KO mice (right) at P28. Bundle width was measured as marked by the dashed line above the genu in the left panel. Representative, anatomically matched sections are shown. Scale bar, $500 \mu \mathrm{m}$, applies to both panels. B, Quantification of images as in $\boldsymbol{A}$ showed in WT a width reduction of the suprapyramidal mossy fiber bundle between P14 and P28. Mossy fibers in SynCAM $1 \mathrm{KO}$ mice did not undergo this developmental pruning, resulting in widened bundles at P28 ( $n=4$ male mice each, 24 measurements per animal; 2 -way ANOVA with Bonferroni's post test) C, Compared with WT mice at P28, SynCAM 1 K0 animals showed increased Timm's staining of mossy fiber terminals in (A3 stratum lucidum (sl; marked by dashed lines). Representative, anatomically matched sections are shown. Scale bar, $500 \mu \mathrm{m}$, applies to both panels. D, Timm's staining measured from images as in C was increased in the K0 compared with WT littermates. Intensity was normalized to background in CA1 ( $n=4$ male mice each, $2-3$ sections per animal; Student's $t$ test). $\boldsymbol{E}$, Density of NeuN-positive neuronal nuclei in DG was unaffected by loss of SynCAM 1 ( $n=7$ sections each from $2-3$ male mice per genotype; Student's $t$ test).

modest, reflected contributions of SynCAM 1 to mossy fiber refinement, including a developmental pruning of mossy fiber bundle width.

Mossy fibers form large terminals in the CA3 region which can be labeled using Timm's staining that detects zinc contained by these synapses and we performed Timm's staining to visualize the lamina innervation of mossy fibers (Fig. 2C). SynCAM $1 \mathrm{KO}$ mice at P28 showed $24 \pm 8.1 \%(p=0.013)$ elevated Timm's staining in CA3 compared with WT controls (Fig. 2D). The changes were not secondary to increased neuronal number because the density of NeuN-positive cell bodies was not altered in $\mathrm{KO}$ animals in either the DG (Fig. 2E; DG WT, $702 \pm 17$ NeuN-positive cells per $1 \times 10^{6} \mu \mathrm{m}^{3}$; DG KO, $704 \pm 18$ ) or the CA3 area (CA3 WT, $396 \pm 23 ; \mathrm{CA} 3 \mathrm{KO}, 388 \pm 18$ ). These findings indicated that the innervation of targets by mossy fibers is altered in absence of SynCAM 1.

\section{SynCAM 1 loss reduces excitatory synaptic connectivity in $\mathrm{CA} 3$}

SynCAM 1 is required in the CA1 area for the formation and maintenance of excitatory Schaffer collateral inputs onto pyramidal neurons (Robbins et al., 2010). We tested to what extent this protein contributes in CA3 to excitatory inputs. We first analyzed the expression of SynCAM 1 by immunohistochemistry at P28 (Fig. 3A). Although our immunohistochemical staining did not detect enrichment at synapses in CA3, SynCAM 1 appeared to surround excitatory terminals positive for vGlutl, consistent with its localization to the plasma membrane of mossy fibers and their terminals. We next immunostained hippocampal sections from WT and SynCAM $1 \mathrm{KO}$ mice at P28 for the excitatory presynaptic vesicle protein vGlut1 and the postsynaptic scaffold protein PSD-95 (Fig. 3B). Synaptic staining was analyzed in CA3 stratum lucidum, where mossy fibers synapse on proximal dendritic segments of CA3 neurons. As reported previously (Kaneko et al., 2002), mossy fiber terminals were intensely labeled with vGlut1. PSD-95 staining displayed a punctate pattern, with larger puncta enriched in the stratum lucidum, similar to vGlut1 and as described previously (Matsuda et al., 2016). The density of vGlut1 puncta in CA3 stratum lucidum was not changed in SynCAM $1 \mathrm{KO}$ mice, though we measured a nonsignificant trend toward smaller vGlutl puncta in the KO (data not shown). Because the loss of SynCAM 1 reduces the number of excitatory synapses in CA1 stratum radiatum (Robbins et al., 2010), we determined to what extent the density of excitatory postsynaptic sites was changed in CA3 stratum lucidum in the absence of SynCAM 1. Quantifying postsynaptic PSD-95 puncta from the 

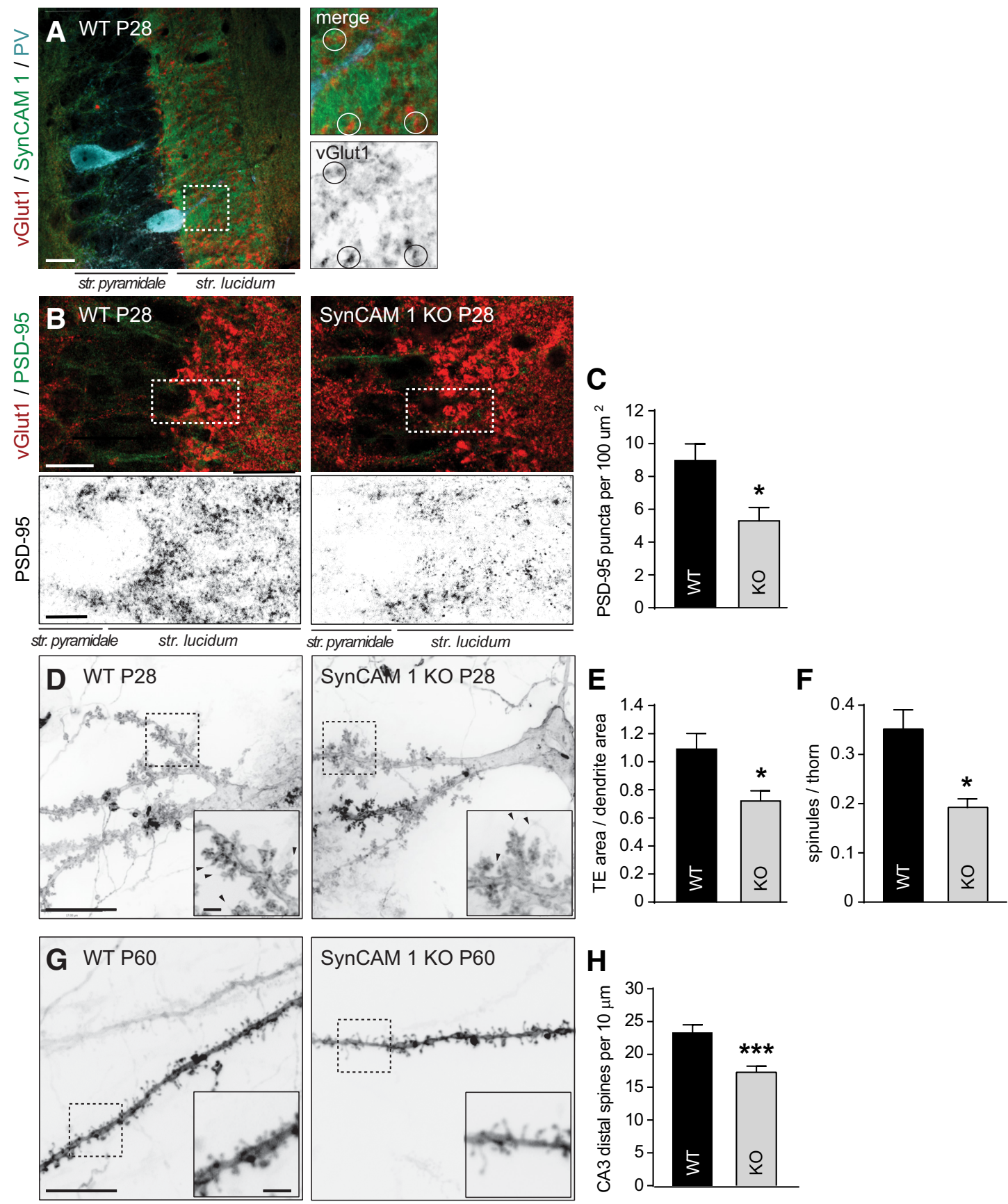

Figure 3. Excitatory postsynaptic changes in the CA3 area of SynCAM $1 \mathrm{KO}$ mice include smaller TEs and fewer distal spines in pyramidal neurons. $A$, Left, Immunostaining of a hippocampal tangential section from WT mice at P28 labeled with anti-vGlut1 (red), anti-SynCAM 1 (green), and anti-PV (cyan) antibodies. A maximum projection of 3 optical sections taken at $0.5 \mu \mathrm{m}$ intervals obtained by high-resolution confocal microscopy in the CA3 region is shown. Right, Enlarged panels of the area boxed on the left depicting vGlut1-positive large mossy fiber terminals. Circles mark vGlut1 puncta surrounded by SynCAM 1. Scale bar in overview image, $20 \mu \mathrm{m}$. B, Confocal images of hippocampal CA3 areas coimmunostained for presynaptic vGlut1 (red) and postsynaptic PSD-95 (green) from anatomically matched WT and K0 sections at P28. Boxed areas are enlarged below, showing the green channel with PSD-95 signal. Single optical $0.8 \mu \mathrm{m}$ sections obtained by high-resolution confocal microscopy are shown. Scale bars: overview, $20 \mu \mathrm{m}$; enlarged panel, $10 \mu \mathrm{m}$. C, Reduction of PSD-95 puncta density in K0 CA3 stratum lucidum measured from images as in $\boldsymbol{B}$. (WT, $n=3$ mice with data from $4-11$ sections each; $\mathrm{K} 0, n=4$ mice with data from $4-11$ sections each). $\boldsymbol{D}$, Dil labeling of primary and secondary dendritic segments from hippocampal CA3 pyramidal neurons showing TEs. Anatomically matched WT and KO sections were obtained at P28. Insets show enlarged areas boxed in the overview images and arrowheads mark protruding TE spinules. Scale bars: overview, $20 \mu \mathrm{m}$; insets, $5 \mu \mathrm{m}$; apply to both panels. $\boldsymbol{E}$, Smaller TEs in CA3 pyramidal neurons of SynCAM $1 \mathrm{~K} 0$ mice. TE surface area on secondary dendrites from images as in $\boldsymbol{D}$ was normalized to the segment area from which they emanate ( $n=3$ male mice each; $2-3$ neurons per mouse with $1-2$ dendritic branches per neuron). $\boldsymbol{F}$, Fewer spinules emanate from TEs in SynCAM $1 \mathrm{~K} 0$ mice ( $n=2-3$ male mice each, 2-3 neurons per animal).G,Secondary dendritic segments of hippocampal CA3 neurons labeled with Dil. Anatomically matched WT and K0 sections were obtained at P60. Insets show enlarged areas marked in the overview. Scale bar overview $10 \mu \mathrm{m}$; inset, $2 \mu \mathrm{m}$; apply to both panels. $\boldsymbol{H}$, Fewer dendritic spines in CA3 pyramidal neurons lacking SynCAM 1. Analysis was performed on distal segments of secondary and also tertiary dendrites from images as in G. (3 male mice each; $2-3$ neurons per animal, one dendritic branch per neuron; Student's $t$ test).

same sections where vGlutl data were obtained (Fig. $3 B$ ), we measured a reduction of PSD-95 puncta density by $41 \pm 11 \%$ $(p=0.036)$ in the CA3 stratum lucidum of KO mice (Fig. 3C; WT, $8.9 \pm 1.03$ per $100 \mu \mathrm{m}^{2}$; KO, $\left.5.2 \pm 0.81\right)$.
Fewer TEs and distal spines in CA3 pyramidal neurons upon SynCAM 1 loss

To measure postsynaptic specializations at P28, we performed biolistic labeling with the dye DiI to image dendrites and spines of 
CA3 pyramidal neurons. Our focus was first on TEs, cherryblossom like protrusions along apical dendrites close to the soma of CA3 pyramidal cells, through which they receive inputs from large mossy fiber terminals (Chicurel and Harris, 1992; Wilke et al., 2013; Fig. 3D). With respect to TE density, a previous study of SynCAM $1 \mathrm{KO}$ mice had not revealed a significant decrease (Wilke et al., 2012). We tested this using DiI labeling and observed a trend toward fewer TE in SynCAM $1 \mathrm{KO}$ mice (WT, $1.47 \pm 0.25 \mathrm{TE}$ per $10 \mu \mathrm{m}$ dendrite, $\mathrm{KO}, 0.88 \pm 0.12)$ that did not reach significance $(p=0.054)$. We extended this analysis and assessed TE size along CA3 secondary dendrites. The ratio of individual TE areas relative to the area of the dendritic segment from which they emerge was reduced by $34 \pm 14 \%(p=0.038)$ in SynCAM $1 \mathrm{KO}$ animals, indicating smaller TEs (Fig. 3E). This result agreed with the reduced PSD-95 staining in the CA3 stratum lucidum of $\mathrm{KO}$ mice (Fig. 3C). TEs of KO mice also had $46 \pm$ $15 \%(p=0.010)$ fewer spinules, or small projections, than WT controls (Fig. $3 F$ ).

In addition to TE inputs, CA3 pyramidal neurons receive excitatory inputs from associational and commissural CA3-CA3 projections and from the entorhinal cortex via the perforant path (Witter, 2007). These inputs occur along more distal dendritic segments of CA3 pyramidal neurons. Dendritic spine density of CA3 neurons along these distal segments was reduced by $26 \pm$ $6.3 \%(p=0.0004)$ in the absence of SynCAM 1 (Fig. 3G,H; WT, $23.4 \pm 1.1$ spines per $10 \mu \mathrm{m}$ dendrite, $\mathrm{KO}, 17.3 \pm 0.9 ; p=0.0003$, $n=3$ mice). These changes of distal spines in $\mathrm{KO}$ mice were due to a reduction of the predominant mushroom type spines by $27 \pm 7.0 \%$ and the less abundant stubby spines by $32 \pm 7.8 \%$, whereas the small fraction of thin spines was not significantly affected (data not shown). We additionally used DiI labeling to measure spine density in CA1 stratum radiatum of $\mathrm{KO}$ mice and found $18 \pm 5.2 \%$ fewer spines (CA1 WT, $23.5 \pm 1.0$ spines per $10 \mu \mathrm{m}$ dendrite, $\mathrm{CA} 1 \mathrm{KO}, 19.3 \pm 1.0 ; p=0.008, n=3$ mice; $p=0.014)$, in agreement with a previous analysis by Golgi staining (Robbins et al., 2010). This reduction was also due to fewer mushroom and stubby spines (data not shown). Loss of SynCAM 1 therefore reduces the number of TE and distal spines through which CA3 pyramidal neurons receive excitatory inputs.

\section{SynCAM 1 organizes excitatory inputs onto PV-positive interneurons in CA3}

Mossy fibers from granule cells in the DG innervate pyramidal CA3 neurons preferentially through large mossy boutons, whereas they contact interneurons via small en passant or filopodial terminals (Acsády et al., 1998). Granule cells innervate GABAergic target neurons more frequently than pyramidal neurons (Acsády et al., 1998) and we analyzed roles of SynCAM 1 for this majority population of mossy fiber targets. Using tangential sectioning (Fukuda and Kosaka, 2000), we visualized dendrites of PV-positive, fast-spiking GABAergic interneurons in CA3 and performed co-immunostaining for vGlut1 and PV (Fig. 4A). The density of vGlut1 puncta on PV-positive dendrites was significantly decreased in SynCAM 1 KO mice by $27 \pm 10 \%$ compared with WT controls ( $p=0.010$; Fig. $4 B)$. A subset of PV-positive dendrites was even devoid of vGlut1 puncta upon lack of SynCAM 1, which was never observed in WT mice. This revealed a novel biological role of SynCAM 1 in controlling excitatory inputs onto GABAergic interneurons.

We next addressed whether loss of SynCAM 1 resulted in postsynaptic changes at excitatory inputs to PV-positive interneurons. The glutamate receptor subunits GluA4 and GluA1 are prominently expressed in these neurons in the hippocampus (Catania et al., 1998) and we first analyzed GluA4 because it regulates synaptic drive onto PV-positive interneurons (Pelkey et al., 2015). Immunohistochemical analysis of GluA4 in dendrites of PV-positive interneurons did not show an effect of SynCAM 1 loss on GluA4 expression (Fig. 4C,D). However, we measured a strong reduction of GluA1 by $77 \pm 27 \%(p=0.026)$ along PVpositive dendrites in SynCAM $1 \mathrm{KO}$ mice (Fig. 4E, F; WT, $10.6 \pm$ 2.8 puncta per $100 \mu \mathrm{m}^{2} \mathrm{PV}+$ dendrite; $\mathrm{KO}, 2.5 \pm 1.4$ ). These results support that SynCAM 1 loss reduces excitatory inputs onto PV-positive interneurons in the CA3 area and can selectively affect their postsynaptic receptor composition.

\section{Loss of SynCAM 1 enhances CA3 network responses to mossy fiber stimulation}

How does the concomitant reduction of excitatory inputs to PVpositive inhibitory interneurons and to CA3 pyramidal cells affect CA3 excitability in SynCAM $1 \mathrm{KO}$ mice? To address this question, field EPSPs (fEPSPs) were recorded in CA3 stratum radium in response to electrical stimulation of mossy fibers. fEPSP amplitude and slope were quantified while stimulus duration was increased from 50 to $750 \mu$ s in $50 \mu$ s intervals. In SynCAM $1 \mathrm{KO}$ animals, the slope and amplitude of fEPSPs were increased significantly compared with WT animals for weak (50 $\mu$ s stimulation) and strong (750 $\mu$ s) mossy fiber stimulation ( $p<$ 0.001 ; Fig. $5 A, B$ ). To determine whether mossy fiber excitability was altered by the loss of SynCAM 1, we varied the stimulus duration from 50 to $750 \mu$ s in $50 \mu$ s increments while quantifying fEPSP parameters. After normalizing to the maximum fEPSP, we found no difference in the scaling of synaptic activation (Fig. 5C). The minimum stimulus required to evoke an EPSP $>0.05 \mathrm{mV}$ in amplitude was also similar for WT and KO animals (Fig. 5D). This indicated that mossy fiber excitability was not changed upon loss of SynCAM 1. We also examined short-term plasticity of mossy fiber-CA3 connections by examining fEPSP properties during paired pulse stimulation (100 $\mu$ s interstimulus interval) and during train stimulation (10 stimulations at $20 \mathrm{~Hz}$ ). No changes in fEPSP amplitude or slope were seen for either stimulation paradigm between WT and SynCAM $1 \mathrm{KO}$ animals (data not shown). These results indicated that the CA3 area is hyperexcitable when SynCAM 1 is absent.

We next investigated whether the increased mossy fiber $\rightarrow$ CA3 fEPSPs in SynCAM 1 KO mice occurred due to a decreased excitatory drive onto inhibitory interneurons in CA3 and a subsequent reduction of feedforward inhibition. Our histochemical studies showing decreased vGlut1 inputs and glutamate receptor expression in CA3 interneurons (Fig. $4 E, F$ ) supported this notion. If a reduction in feedforward inhibition resulted in increased mossy fiber $\rightarrow$ CA3 fEPSPs, then blocking $G_{A B A}$ receptors should decrease fEPSPs differences between WT and SynCAM $1 \mathrm{KO}$ animals. To test this, we recorded stimulusevoked fEPSPs in the presence of $10 \mu \mathrm{M}$ SR-95531 (gabazine), a $\mathrm{GABA}_{\mathrm{A}}$ receptor antagonist. In the presence of SR-95531, electrical stimulation of mossy fibers (DG $\rightarrow$ CA3) evoked large fEPSPs recorded in WT CA3, as expected. fEPSP slope and amplitude were nearly identical between WT and SynCAM 1 KO mice and no significant differences were observed in presence of SR95531 (Fig. 5E, F). This supports that SynCAM $1 \mathrm{KO}$ animals exhibit decreased feedforward inhibition and hence enhanced excitability in CA3. 

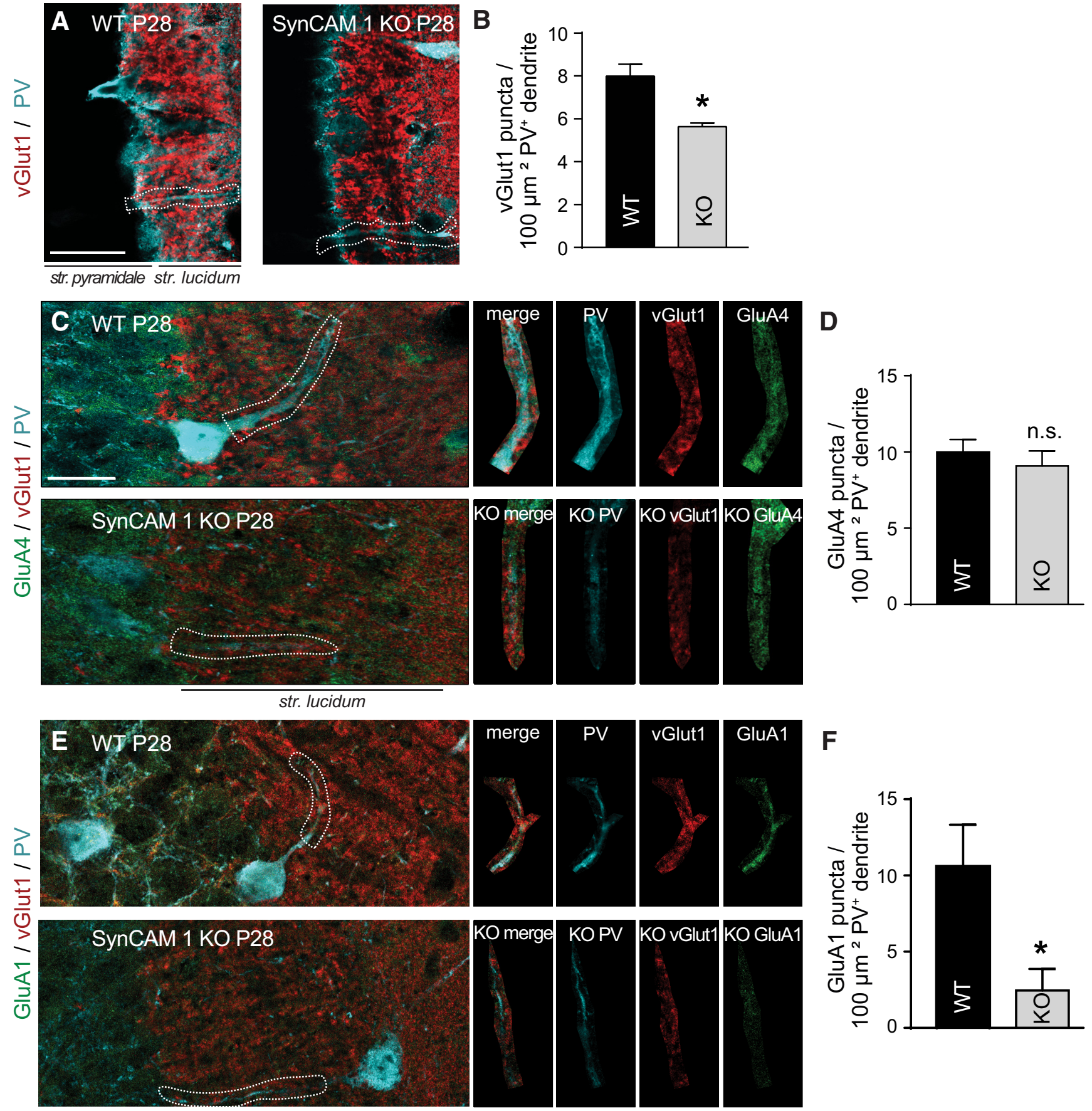

$\mathbf{F}$
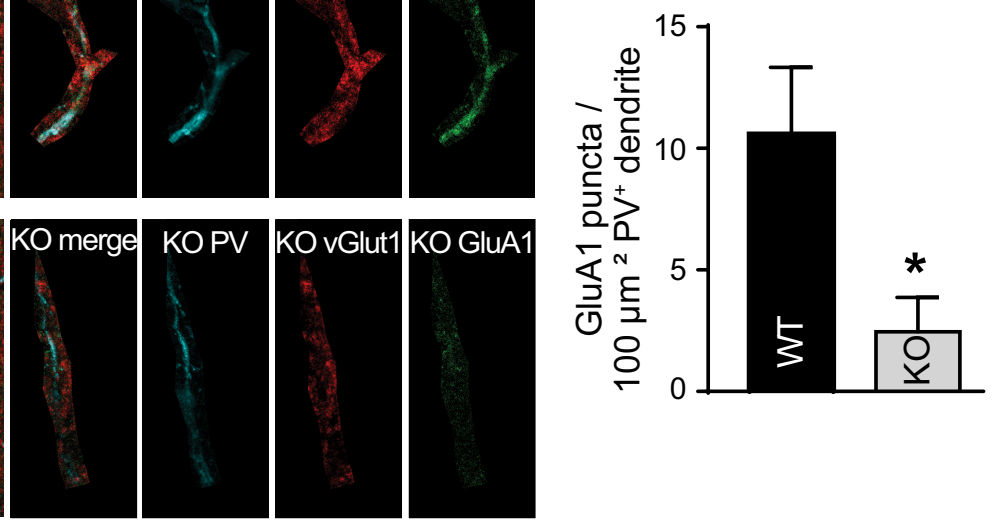

Figure 4. Loss of SynCAM 1 reduces excitatory inputs onto PV-positive inhibitory interneurons in CA3. A, Immunostaining of hippocampal sections from WT (left) and SynCAM 1 K0 mice (right) at P28 with anti-vGlut1 (red) and anti-PV (cyan) antibodies. Single optical $0.8 \mu \mathrm{m}$ sections obtained by high-resolution confocal microscopy are shown. Sections were anatomically matched and cut parallel to the long hippocampal axis to visualize PV-filled primary dendrites. Scale bar, $50 \mu \mathrm{m}$. B, Quantification of images as in $\boldsymbol{A}$ showed that PV-positive interneurons in SynCAM 1 KO hippocampus received fewer excitatory, vGlut1-positive inputs than WT controls ( $n=3$ WT mice with data from a total of 96 dendritic segments and 3 KO with total 106 dendritic segments). $\boldsymbol{C}$, $\boldsymbol{E}$, Immunostaining of hippocampal sections from WT and SynCAM $1 \mathrm{~K} 0$ mice at P28 with anti-vGlut1 (red), anti-PV (cyan), and anti-GluA4 (C) or anti-GluA1 antibodies ( $\boldsymbol{E}$; green). Single optical $0.8 \mu \mathrm{m}$ sections obtained by high-resolution confocal microscopy are shown. Representative PV-positive dendritic segments marked by dashed lines in the left panels are enlarged at right. Scale bars: overview, $30 \mu \mathrm{m}$; applies to all overview panels. $\boldsymbol{D}, \boldsymbol{F}$, Quantification of the density of GluA4 (D) or GluA1 puncta $(\boldsymbol{F})$ on PV-positive dendrite areas from images as in $\boldsymbol{C}$ and $\boldsymbol{E}$, respectively, shows a reduction of GluA1 in SynCAM $1 \mathrm{KO}$ mice ( $\boldsymbol{D}: n=7$ WT mice with data from total 129 dendritic segments and $8 \mathrm{~K} 0$ with total 133 dendritic segments; $\boldsymbol{F}: n=4$ WT mice from 79 dendritic segments and $5 \mathrm{KO}$ with 94 dendritic segments).

Impaired performance in associative memory tasks involving the CA3 area in SynCAM 1 KO mice

We next determined behavioral consequences relevant to the CA3 network changes in SynCAM $1 \mathrm{KO}$ mice. We used animals at P28, the age when significant changes were measured by DTI and histology and when CFC can be performed (Pattwell et al., 2011).
We first used CFC, a learning task in which the CA3 region provides contextual information for rapid encoding of fear memory (Kesner, 2007). We tested both short-term (1 h) and long-term $(24 \mathrm{~h})$ memory by quantifying the time mice spent freezing. The mild foot shock that we used made this learning task comparatively difficult. WT animals still learned this task well, as shown by 

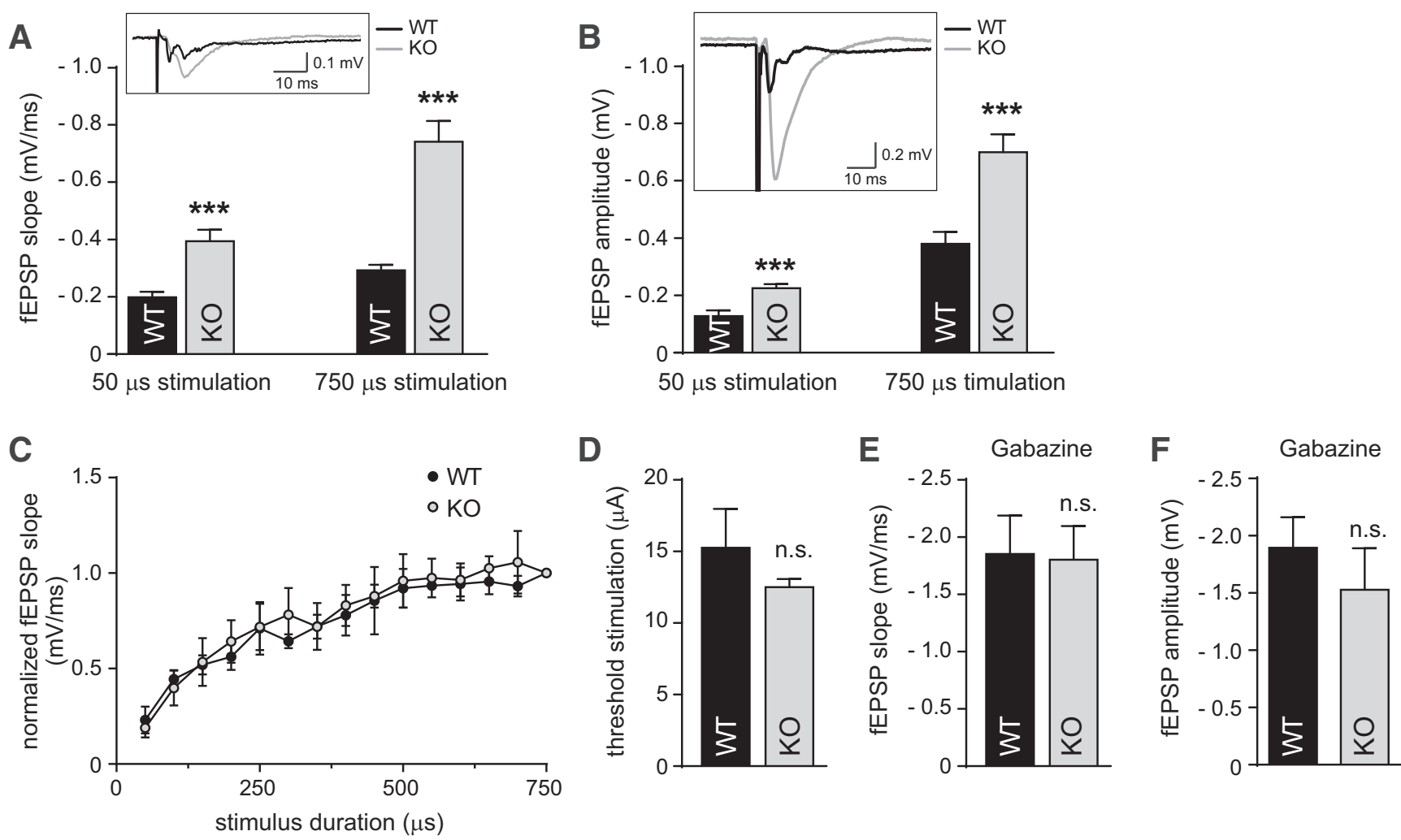

Figure 5. Mossy fiber/CA3 field potentials are enhanced in SynCAM $1 \mathrm{KO}$ mice. A, CA3 fEPSP maximum negative slope evoked by electrical stimulation of mossy fibers. Both brief (50 $\mu$ s) and prolonged (750 $\mu \mathrm{s}$ ) electrical stimulations were given. Recordings were obtained from mice between P28 and P37. For all conditions measured, SynCAM 1 K0s had enhanced mossy fiber/CA3 fEPSPs. The inset shows example fEPSP traces from a WT (black) and SynCAM $1 \mathrm{KO}$ (gray) mouse with a $50 \mu$ s stimulation pulse. ${ }^{* *} p<0.001$ ( $n=3$ male mice per group). B, Evoked CA3 fEPSP amplitudes were measured as described in $A$. The inset shows example fEPSP traces from a WT (black) and SynCAM1 KO (gray) mouse with a $750 \mu$ s stimulation pulse. C, Peak-normalized fEPSPs showed similar scaling for both WT and KO mice, indicating no change in input/output relationship or presynaptic function. D, Threshold stimulation was not significantly different between WT and KOs, indicating similar axonal excitability. $\boldsymbol{E}, \boldsymbol{F}$, Blockade of GABAA receptors with $10 \mu \mathrm{M}$ SR-95531 (gabazine) increased mossy fiber to CA3 fEPSP responses in WT mice and eliminated differences between genotypes. fEPSP maximum slope $(\boldsymbol{E})$ and maximum amplitude $(\boldsymbol{F})$ were quantified in WT $(n=8)$ and SynCAM $1 \mathrm{KO}(n=10)$ mice. No significant differences were seen in either measure (slope, $p=0.91 ;$ amplitude, $p=0.44$ ).

frequent freezing $1 \mathrm{~h}$ after CFC (Fig. 6A). In contrast, SynCAM 1 $\mathrm{KO}$ animals exhibited significant impairment in short-term memory compared with WT (Fig. 6A). This deficit in SynCAM 1 $\mathrm{KO}$ mice persisted $24 \mathrm{~h}$ after training and thus affected long-term memory. To further explore the effects of SynCAM 1 loss on tasks that involve the CA3 area, we used the inhibitory avoidance test (Martínez et al., 2002; Cravens et al., 2006). As was the case with CFC, animals received a shock in a specific space and context. They were then presented with a choice to avoid or reenter the context in which they had received the shock. Animals lacking SynCAM 1 showed impaired short- and long-term fear memory compared with WT controls (Fig. 6B).

\section{Discussion}

Our results demonstrate that the synapse-organizing adhesion molecule SynCAM 1 has pronounced effects on neuronal connectivity in the hippocampal CA3 area. In agreement with the changes in the macromolecular organization of CA3 measured as FA reduction in the absence of SynCAM 1, the developmental refinement of mossy fiber projections was altered in $\mathrm{KO}$ mice. These impairments were accompanied by a reduction of excitatory mossy fiber inputs to both pyramidal neurons and PVpositive GABAergic interneurons and increased CA3 excitability. In turn, associative memory tasks involving CA3 were impaired in SynCAM 1 KO.

Unbiased high-resolution DTI mapping of SynCAM $1 \mathrm{KO}$ mice led us to investigate the CA3 area and future studies of the other regions with altered FA can further evaluate DTI use to survey connectivity changes in mouse models. The FA reduction in CA3 upon loss of SynCAM 1 was in agreement with our observation of structurally less refined mossy fiber bundles because changes in axonal packing can cause variations in FA. Similar roles of adhesion proteins in organizing mossy fiber bundles were observed previously for NCAM (Cremer et al., 1997; Seki and Rutishauser, 1998) and $N$-cadherin (Bekirov et al., 2008). Unlike NCAM and the L1 family of adhesion proteins, which control axon outgrowth and guidance (Maness and Schachner, 2007) and the early developmental functions of SynCAM 1 in axon pathfinding in the spinal cord of chicks (Niederkofler et al., 2010; Frei et al., 2014), we did not observe effects of SynCAM 1 loss on mossy fiber outgrowth in the CA3 area of mice. We consider that the impaired refinement of mossy fiber width in SynCAM $1 \mathrm{KO}$ mice may reflect impaired target interactions for two reasons. First, the phenotype of impaired mossy fiber width pruning arises late in development between P14 and P28, a period when SynCAM 1 acts to first induce excitatory synapses and then maintains them (Biederer et al., 2002; Fogel et al., 2007; Robbins et al., 2010). Second, the increase in Timm's staining indicates a more dispersed mossy fiber termination area upon loss of SynCAM 1.

Indeed, our analysis of the targets of mossy fibers supports that SynCAM 1 affects excitatory synaptic connectivity in CA3. The reduction of distal spine number that we found in CA3 pyramidal neurons upon loss of SynCAM 1 is consistent with its 

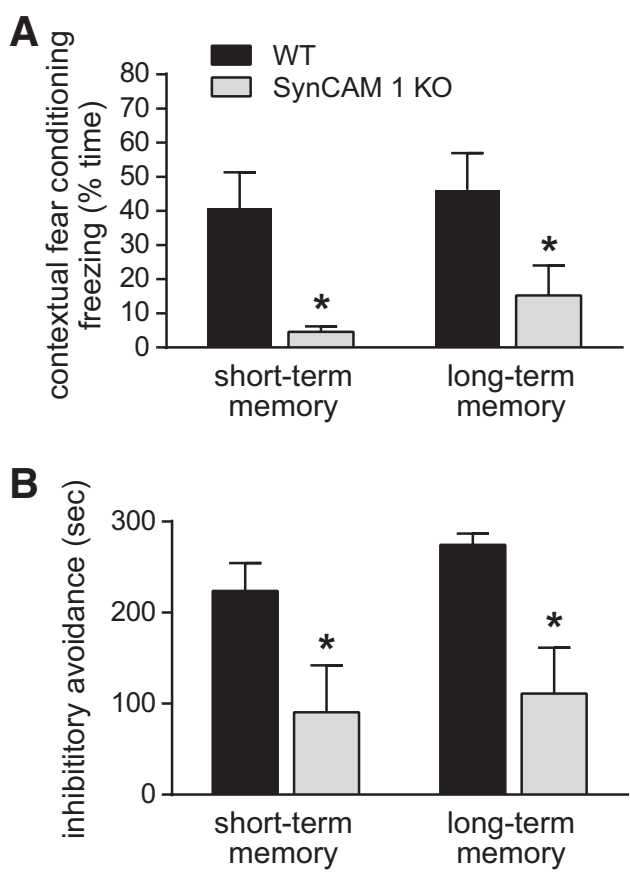

Figure 6. Associative memory tasks involving CA3 are impaired in SynCAM $1 \mathrm{KO}$ mice. $A$, CFC showed decreased short-term memory (STM) and long-term memory (LTM) in P28 KO mice lacking SynCAM 1. STM was tested $1 \mathrm{~h}$ and LTM $24 \mathrm{~h}$ after conditioning ( $n=6$ male mice each). $\boldsymbol{B}$, Inhibitory avoidance tests showed decreased STM and LTM in mice lacking SynCAM 1. STM was tested $1 \mathrm{~h}$ and LTM $24 \mathrm{~h}$ after conditioning ( $n=6$ male mice each; Student's $t$ test, $\left.{ }^{*} p<0.05\right)$.

previously reported function of promoting excitatory inputs onto excitatory neurons in CA1 (Robbins et al., 2010). SynCAM 1 additionally shapes TEs, complex postsynaptic structures for mossy fiber inputs that are particular to CA3 pyramidal neurons and considered critical for long-term spatial memory (RamírezAmaya et al., 2001; Sandi et al., 2003; Wilke et al., 2013). SynCAM 1 loss also reduces the number of spinules emanating from TEs, thin protrusions that may function to remodel these synaptic junctions (Spacek and Harris, 2004; Lanore et al., 2012). These effects of SynCAM 1 on TEs extend the finding that cadherin-9 affects TE shape (Williams et al., 2011) and that fewer of these structures were reported in NCAM KO mice (Cremer et al., 1997), with EphA4 signaling complementing these adhesive interactions in TE development (Galimberti et al., 2010). Further, our results support that SynCAM 1 affects excitatory presynaptic and postsynaptic markers differentially in CA3, with vGlut1 puncta number unchanged and PSD-95 puncta being less abundant. It will be of interest to determine whether SynCAM 1 anchors axonal sites containing presynaptic proteins to postsynaptic specializations, resulting in ectopic presynaptic assemblies in SynCAM $1 \mathrm{KO}$ mice.

Our findings in addition reveal an unexpected role of SynCAM 1 in in the development of excitatory synapses onto inhibitory neurons. Specifically, the loss of SynCAM 1 reduces the number of excitatory mossy fiber inputs to PV-positive GABAergic interneurons. Consistent with this reduction, we detected a strong decrease in the density of GluA1-immunoreactive puncta on PV-positive dendrites in CA3 stratum lucidum of SynCAM 1 KO mice. SynCAM 1 loss had no effect on the expression of GluA4, another glutamate receptor subunit highly expressed in these interneurons (Chang et al., 2010). This contrasts with the role of pentraxins, which promote the development of
GluA4, but not GluA1-containing synapses, on PV-positive interneurons in the hippocampus (Chang et al., 2010; Pelkey et al., 2015). SynCAM 1 is predominantly expressed in excitatory neurons across forebrain (Thomas et al., 2008; Yamada et al., 2013), but in the CA3 area, it is additionally expressed in $\sim 70 \%$ of PV-positive cells (Yamada et al., 2013). Because SynCAM 1 acts at postsynaptic sites to induce presynaptic specializations (Biederer et al., 2002; Fogel et al., 2007), the effects that we report here on excitatory inputs on PV-positive interneurons are consistent with a synaptogenic role of this protein in GABAergic neurons in this hippocampal area, which can now be tested. It will be of interest to determine which trans-synaptic partner SynCAM 1 engages to perform this novel function and whether SynCAM 1 recruits GluA1 to synapses in PV-positive interneurons.

The net effect of these excitatory input imbalances is an increase in CA3 excitability. Mossy fibers are estimated to make $50 \times$ more synaptic contacts onto interneurons than to pyramidal cells (Acsády et al., 1998). These synapses mediate powerful feedforward inhibitory drive and are 30\% less abundant in SynCAM 1 $\mathrm{KO}$ animals, a reduction that agrees with the impaired constraint of CA3 excitability in these mice determined by measuring fEPSP amplitudes. The lower excitatory drive onto PV-positive interneurons in the absence of SynCAM 1 could thus override the parallel decrease in excitatory inputs to pyramidal neurons. Axonal excitability and short-term plasticity are normal in the CA3 of SynCAM $1 \mathrm{KO}$ animals and the increases in fEPSPs thus do not appear to be due to presynaptic dysfunction. The CA3 area is characterized by abundant recurrent collateral excitatory connectivity and disinhibition in this region is especially important because its recurrent connectivity generates synchronized neuronal activity (Li et al., 1994). This coherent CA3 activity is essential for proper activation of downstream CA1 neurons and mediates population bursting essential to CA1 fast ripples (Nakashiba et al., 2008). When inhibition is compromised, however, CA3 can act as a generator of seizures and interictal activity. Whether the loss of SynCAM 1 leads to severe network dysfunction in vivo remains to be tested.

Aiming to complement our histochemical and electrophysiological results, we found that the synaptic imbalances in the CA3 area of SynCAM 1 KO mice are correlated with impaired hippocampus-dependent associative fear memory. This agrees with the role of the CA3 area as an auto-association network in which inhibitory connections allow for sparse representations (Rolls, 2013) and with the critical role of CA3 outputs in contextual fear memory formation (Nakashiba et al., 2008). When interpreting this behavioral aberration in absence of SynCAM 1, it also needs to be considered that disorganized mossy fiber distribution and bundling and improper CA3 targeting can be correlated with impaired contextual fear memory, as in NCAM KO mice (Cremer et al., 1997; Stork et al., 2000). In addition, this analysis was performed in constitutive $\mathrm{KO}$ mice and the impaired fear conditioning could reflect contributions of SynCAM 1 in brain regions other than CA3 (Fendt and Fanselow, 1999). SynCAM $1 \mathrm{KO}$ mice were previously found to better form memories in the Morris water maze, a spatial reference task that involves the CA1 area, when aged mice were tested (Robbins et al., 2010). Decreased fear conditioning and increased memory in the Morris water maze can occur in parallel (McGirr et al., 2016). The varied performance of SynCAM $1 \mathrm{KO}$ mice in fear conditioning and spatial memory could be age dependent because we tested young animals in the present study, but the different performance in these tasks may reflect distinct physiological roles of this protein in CA3 and CA1. 
SynCAM 1 affects the excitatory connectivity of interneurons and pyramidal neurons in the CA3 area in parallel to other mechanisms. These include the Ig adhesion protein Kirrel3, which organizes excitatory mossy fiber inputs to CA3 interneurons without altering excitatory transmission to CA3 pyramidal neurons (Martin et al., 2015); $\mathrm{N}$-cadherin, which modulates AMPA receptor localization, but not excitatory synapse number (Nikitczuk et al., 2014); and neuroligin-4, which controls the assembly of inhibitory synaptic inputs to CA3 pyramidal neurons (Hammer et al., 2015). Complementing these cell-type-specific mechanisms, SynCAM 1 contributes to setting CA3 excitability by balancing excitatory inputs onto both GABAergic interneurons and pyramidal neurons.

This work used an unbiased imaging approach to identify roles of SynCAM 1 in the CA3 area to organize excitatory inputs to PV-positive GABAergic interneurons in addition to controlling excitatory synapses to glutamatergic neurons. The connectivity of these distinct neuron types and the excitability of their network can thus be balanced by the same synapse-organizing mechanism.

\section{References}

Acsády L, Kamondi A, Sík A, Freund T, Buzsáki G (1998) GABAergic cells are the major postsynaptic targets of mossy fibers in the rat hippocampus. J Neurosci 18:3386-3403. Medline

Bekirov IH, Nagy V, Svoronos A, Huntley GW, Benson DL (2008) Cadherin- 8 and $N$-cadherin differentially regulate pre- and postsynaptic development of the hippocampal mossy fiber pathway. Hippocampus 18:349-363. CrossRef Medline

Benson DL, Colman DR, Huntley GW (2001) Molecules, maps and synapse specificity. Nat Rev Neurosci 2:899-909. CrossRef Medline

Betancur C, Sakurai T, Buxbaum JD (2009) The emerging role of synaptic cell-adhesion pathways in the pathogenesis of autism spectrum disorders. Trends Neurosci 32:402-412. CrossRef Medline

Biederer T, Sara Y, Mozhayeva M, Atasoy D, Liu X, Kavalali ET, Südhof TC (2002) SynCAM, a synaptic adhesion molecule that drives synapse assembly. Science 297:1525-1531. CrossRef Medline

Catania MV, Bellomo M, Giuffrida R, Giuffrida R, Stella AM, Albanese V (1998) AMPA receptor subunits are differentially expressed in parvalbuminand calretinin-positive neurons of the rat hippocampus. Eur J Neurosci 10:3479-3490. CrossRef Medline

Chahboune H, Ment LR, Stewart WB, Ma X, Rothman DL, Hyder F (2007) Neurodevelopment of C57B/L6 mouse brain assessed by in vivo diffusion tensor imaging. NMR Biomed 20:375-382. CrossRef Medline

Chang MC, Park JM, Pelkey KA, Grabenstatter HL, Xu D, Linden DJ, Sutula TP, McBain CJ, Worley PF (2010) Narp regulates homeostatic scaling of excitatory synapses on parvalbumin-expressing interneurons. Nat Neurosci 13:1090-1097. CrossRef Medline

Chicurel ME, Harris KM (1992) Three-dimensional analysis of the structure and composition of CA3 branched dendritic spines and their synaptic relationships with mossy fiber boutons in the rat hippocampus. J Comp Neurol 325:169-182. CrossRef Medline

Cravens CJ, Vargas-Pinto N, Christian KM, Nakazawa K (2006) CA3 NMDA receptors are crucial for rapid and automatic representation of context memory. Eur J Neurosci 24:1771-1780. CrossRef Medline

Cremer H, Chazal G, Goridis C, Represa A (1997) NCAM is essential for axonal growth and fasciculation in the hippocampus. Mol Cell Neurosci 8:323-335. CrossRef Medline

Duque A, Coman D, Carlyle BC, Bordner KA, George ED, Papademetris X, Hyder F, Simen AA (2012) Neuroanatomical changes in a mouse model of early life neglect. Brain Struct Funct 217:459-472. CrossRef Medline

Fendt M, Fanselow MS (1999) The neuroanatomical and neurochemical basis of conditioned fear. Neurosci Biobehav Rev 23:743-760. CrossRef Medline

Fogel AI, Akins MR, Krupp AJ, Stagi M, Stein V, Biederer T (2007) SynCAMs organize synapses through heterophilic adhesion. J Neurosci 27: 12516-12530. CrossRef Medline

Frei JA, Andermatt I, Gesemann M, Stoeckli ET (2014) The synaptic cell adhesion molecules SynCAMs are involved in sensory axon pathfinding by regulating axon-axon contacts. J Cell Sci 127:5288-5302. CrossRef Medline

Fujita E, Kouroku Y, Ozeki S, Tanabe Y, Toyama Y, Maekawa M, Kojima N, Senoo H, Toshimori K, Momoi T (2006) Oligo-astheno-teratozoospermia in mice lacking RA175/TSLC1/ SynCAM/IGSF4A, a cell adhesion molecule in the immunoglobulin superfamily. Mol Cell Biol 26:718-726. CrossRef Medline

Fukuda T, Kosaka T (2000) Gap junctions linking the dendritic network of GABAergic interneurons in the hippocampus. J Neurosci 20:1519-1528. Medline

Galimberti I, Bednarek E, Donato F, Caroni P (2010) EphA4 signaling in juveniles establishes topographic specificity of structural plasticity in the hippocampus. Neuron 65:627-642. CrossRef Medline

Giza JI, Jung Y, Jeffrey RA, Neugebauer NM, Picciotto MR, Biederer T (2013) The Synaptic Adhesion Molecule SynCAM 1 contributes to cocaine effects on synapse structure and psychostimulant behavior. Neuropsychopharmacology 38:628-638. CrossRef Medline

Hammer M, Krueger-Burg D, Tuffy LP, Cooper BH, Taschenberger H, Goswami SP, Ehrenreich H, Jonas P, Varoqueaux F, Rhee JS, Brose N (2015) Perturbed hippocampal synaptic inhibition and gamma-oscillations in a neuroligin-4 knockout mouse model of autism. Cell Rep 13:516-523. CrossRef Medline

Kaneko T, Fujiyama F, Hioki H (2002) Immunohistochemical localization of candidates for vesicular glutamate transporters in the rat brain. J Comp Neurol 444:39-62. CrossRef Medline

Kesner RP (2007) Behavioral functions of the CA3 subregion of the hippocampus. Learn Mem 14:771-781. CrossRef Medline

Lanore F, Labrousse VF, Szabo Z, Normand E, Blanchet C, Mulle C (2012) Deficits in morphofunctional maturation of hippocampal mossy fiber synapses in a mouse model of intellectual disability. J Neurosci 32:1788217893. CrossRef Medline

Li XG, Somogyi P, Ylinen A, Buzsáki G (1994) The hippocampal CA3 network: an in vivo intracellular labeling study. J Comp Neurol 339:181-208. CrossRef Medline

Maness PF, Schachner M (2007) Neural recognition molecules of the immunoglobulin superfamily: signaling transducers of axon guidance and neuronal migration. Nat Neurosci 10:19-26. CrossRef Medline

Martin EA, Muralidhar S, Wang Z, Cervantes DC, Basu R, Taylor MR, Hunter J, Cutforth T, Wilke SA, Ghosh A, Williams ME (2015) The intellectual disability gene Kirrel3 regulates target-specific mossy fiber synapse development in the hippocampus. eLife 4.

Martínez I, Quirarte G, Díaz-Cintra S, Quiroz C, Prado-Alcalá RA (2002) Effects of lesions of hippocampal fields CA1 and CA3 on acquisition of inhibitory avoidance. Neuropsychobiology 46:97-103. CrossRef Medline

Matsuda K, Budisantoso T, Mitakidis N, Sugaya Y, Miura E, Kakegawa W, Yamasaki M, Konno K, Uchigashima M, Abe M, Watanabe I, Kano M, Watanabe M, Sakimura K, Aricescu AR, Yuzaki M (2016) Transsynaptic modulation of kainate receptor functions by C1q-like proteins. Neuron 90:752-767. CrossRef Medline

McGirr A, Lipina TV, Mun HS, Georgiou J, Al-Amri AH, Ng E, Zhai D, Elliott C, Cameron RT, Mullins JG, Liu F, Baillie GS, Clapcote SJ, Roder JC (2016) Specific inhibition of phosphodiesterase-4B results in anxiolysis and facilitates memory acquisition. Neuropsychopharmacology 41: 1080-1092. CrossRef Medline

Missler M, Südhof TC, Biederer T (2012) Synaptic cell adhesion. In: Synapses (Südhof TC, Sheng M, Sabatini B, eds), pp 31-48. Cold Spring Harbor, NY: Cold Spring Harbor Laboratory.

Nakashiba T, Young JZ, McHugh TJ, Buhl DL, Tonegawa S (2008) Transgenic inhibition of synaptic transmission reveals role of CA3 output in hippocampal learning. Science 319:1260-1264. CrossRef Medline

Nelson SB, Valakh V (2015) Excitatory/inhibitory balance and circuit homeostasis in autism spectrum disorders. Neuron 87:684-698. CrossRef Medline

Niederkofler V, Baeriswyl T, Ott R, Stoeckli ET (2010) Nectin-like molecules/SynCAMs are required for post-crossing commissural axon guidance. Development 137:427-435. CrossRef Medline

Nikitczuk JS, Patil SB, Matikainen-Ankney BA, Scarpa J, Shapiro ML, Benson DL, Huntley GW (2014) N-cadherin regulates molecular organization of excitatory and inhibitory synaptic circuits in adult hippocampus in vivo. Hippocampus 24:943-962. CrossRef Medline

Oguz I, McMurray MS, Styner M, Johns JM (2012) The translational role of 
diffusion tensor image analysis in animal models of developmental pathologies. Dev Neurosci 34:5-19. CrossRef Medline

Papademetris X, Jackowski AP, Schultz RT, Staib LH, Duncan JS (2001) Integrated intensity and point-feature nonrigid registration. Med Image Comput Comput Assist Interv 3216:763-770. Medline

Pattwell SS, Bath KG, Casey BJ, Ninan I, Lee FS (2011) Selective earlyacquired fear memories undergo temporary suppression during adolescence. Proc Natl Acad Sci U S A 108:1182-1187. CrossRef Medline

Paxinos G, Franklin K (2001) The mouse brain in stereotaxic coordinates, Ed 2. San Diego: Academic.

Pelkey KA, Barksdale E, Craig MT, Yuan X, Sukumaran M, Vargish GA, Mitchell RM, Wyeth MS, Petralia RS, Chittajallu R, Karlsson RM, Cameron HA, Murata Y, Colonnese MT, Worley PF, McBain CJ (2015) Pentraxins coordinate excitatory synapse maturation and circuit integration of parvalbumin interneurons. Neuron 85:1257-1272. CrossRef Medline

Perez de Arce K, Schrod N, Metzbower SW, Allgeyer E, Kong GK, Tang AH, Krupp AJ, Stein V, Liu X, Bewersdorf J, Blanpied TA, Lucić V, Biederer T (2015) Topographic mapping of the synaptic cleft into adhesive nanodomains. Neuron 88:1165-1172. CrossRef Medline

Ramírez-Amaya V, Balderas I, Sandoval J, Escobar ML, Bermúdez-Rattoni F (2001) Spatial long-term memory is related to mossy fiber synaptogenesis. J Neurosci 21:7340-7348. Medline

Robbins EM, Krupp AJ, Perez de Arce K, Ghosh AK, Fogel AI, Boucard A, Südhof TC, Stein V, Biederer T (2010) SynCAM 1 adhesion dynamically regulates synapse number and impacts plasticity and learning. Neuron 68:894-906. CrossRef Medline

Rolls ET (2013) The mechanisms for pattern completion and pattern separation in the hippocampus. Front Syst Neurosci 7:74. CrossRef Medline

Sandi C, Davies HA, Cordero MI, Rodriguez JJ, Popov VI, Stewart MG (2003) Rapid reversal of stress induced loss of synapses in CA3 of rat hippocampus following water maze training. Eur J Neurosci 17:24472456. CrossRef Medline

Schwegler H, Heimrich B, Keller F, Renner P, Crusio WE (1988) Strainspecific development of the mossy fiber system in organotypic cultures of the mouse hippocampus. Neurosci Lett 87:7-10. CrossRef Medline

Seki T, Rutishauser U (1998) Removal of polysialic acid-neural cell adhesion molecule induces aberrant mossy fiber innervation and ectopic synaptogenesis in the hippocampus. J Neurosci 18:3757-3766. Medline

Seshadri S, Zeledon M, Sawa A (2013) Synapse-specific contributions in the cortical pathology of schizophrenia. Neurobiol Dis 53:26-35. CrossRef Medline

Shen K, Scheiffele P (2010) Genetics and cell biology of building specific synaptic connectivity. Annu Rev Neurosci 33:473-507. CrossRef Medline

Spacek J, Harris KM (2004) Trans-endocytosis via spinules in adult rat hippocampus. J Neurosci 24:4233-4241. CrossRef Medline

Staffend NA, Meisel RL (2011) DiOlistic labeling in fixed brain slices: phenotype, morphology, and dendritic spines. Curr Protoc Neurosci Chapter 2:Unit 2.13. CrossRef Medline

Stork O, Welzl H, Wolfer D, Schuster T, Mantei N, Stork S, Hoyer D, Lipp H, Obata K, Schachner M (2000) Recovery of emotional behaviour in neural cell adhesion molecule (NCAM) null mutant mice through transgenic expression of NCAM180. Eur J Neurosci 12:3291-3306. CrossRef Medline

Südhof TC (2008) Neuroligins and neurexins link synaptic function to cognitive disease. Nature 455:903-911. CrossRef Medline

Thomas LA, Akins MR, Biederer T (2008) Expression and adhesion profiles of SynCAM molecules indicate distinct neuronal functions. J Comp Neurol 510:47-67. CrossRef Medline

Wilke SA, Hall BJ, Antonios JK, Denardo LA, Otto S, Yuan B, Chen F, Robbins EM, Tiglio K, Williams ME, Qiu Z, Biederer T, Ghosh A (2012) NeuroD2 regulates the development of hippocampal mossy fiber synapses. Neural Dev 7:9. CrossRef Medline

Wilke SA, Antonios JK, Bushong EA, Badkoobehi A, Malek E, Hwang M, Terada M, Ellisman MH, Ghosh A (2013) Deconstructing complexity: serial block-face electron microscopic analysis of the hippocampal mossy fiber synapse. J Neurosci 33:507-522. CrossRef Medline

Williams ME, Wilke SA, Daggett A, Davis E, Otto S, Ravi D, Ripley B, Bushong EA, Ellisman MH, Klein G, Ghosh A (2011) Cadherin-9 regulates synapse-specific differentiation in the developing hippocampus. Neuron 71:640-655. CrossRef Medline

Witter MP (2007) Intrinsic and extrinsic wiring of CA3: indications for connectional heterogeneity. Learn Mem 14:705-713. CrossRef Medline

Yamada A, Inoue E, Deguchi-Tawarada M, Matsui C, Togawa A, Nakatani T, Ono Y, Takai Y (2013) Necl-2/CADM1 interacts with ErbB4 and regulates its activity in GABAergic neurons. Mol Cell Neurosci 56:234-243. CrossRef Medline

Zipursky SL, Sanes JR (2010) Chemoaffinity revisited: Dscams, protocadherins, and neural circuit assembly. Cell 143:343-353. CrossRef Medline 